\title{
Breaking the cycle: a psychological approach to supporting premenstrual syndrome patients
}

\section{Susan Quilliam}

\section{Background}

The issue of premenstrual syndrome (PMS) is one that is very close to my heart - I suffered from it for 35 years until the onset of the menopause, and I regularly receive letters from women whose life problems are underpinned by premenstrual stress. Happily, the medical profession has taken huge strides forward in recent years not only in acknowledging the syndrome, but also in diagnosing and treating it. We are in a hugely better place than when I began to menstruate and my general practitioner told me that since I had admitted that my appalling pain level would still leave me capable of leaving my bed in case of fire, he wouldn't be prescribing me any painkillers!

However, there are still few cohesive models of the psychological structure of PMS. It is labelled as a physiological condition, and the anxiety, depression, anger and guilt that women suffer, along with the devastation that suffering wreaks on couples and families, are seen as inexorably linked to physiology and treated mainly by medical treatment. I'm not underestimating the sterling work done with PMS sufferers by the therapeutic community; but in the medical profession we don't seem to hold a cohesive model of how we can use 'mental approaches' to help PMS patients as we do with, for example, patients who need to stop smoking or lose weight.

\section{Pessimism, optimism}

So it was with an immense sense of excitement that I came across the work of University of Pennsylvania Professor, Martin Seligman. If I may simplify the Seligman elements that seem to me to be the most useful in the PMS context, his theories go like this. Dyed-in-the-wool pessimists take personal blame for the bad things that happen in life, believe that everything is bad and always will be, and feel helpless to change that. Over-the-top optimists, on the other hand, take personal credit for the good things that happen in their lives, believe that everything is good and always will be, and feel personally powerful to sort out the problems.

Here's the hopeful bit. Seligman suggests that while some pessimism is so ingrained that it runs throughout a person's personality, pessimistic thinking patterns can often be shifted to optimistic ones. And certainly many branches of psychotherapy have picked up Seligman's theories and run with them.

\section{PMS pessimism}

Now, we in the medical profession are not psychotherapists. But I venture to suggest that when it comes to PMS in particular, we can usefully learn from Seligman. Because with just a little thought, it's clear that whatever the basic personality of a PMS sufferer, and to

J Fam Plann Reprod Health Care 2008; 34(1): 61-62

\section{Cambridge, UK}

Susan Quilliam, BA, Cert Ed, MNLP, Freelance Writer, Broadcaster and Agony Aunt

Correspondence to: Ms Susan Quilliam.

E-mail: susan@susanquilliam.com whatever extent the root cause of her PMS is physiological, nevertheless the classic emotional symptoms of the condition clearly resemble what Seligman describes as pessimistic thinking.

The letters I receive as an agony aunt echo the phrases that Journal readers must surely hear from PMS patients in the consulting room. The first element, feelings of selfblame and lack of self-belief ("It's all my fault ... I just can't pull myself together ... I'm being stupid"). The second element, the generalising and catastrophising ("My life is ruined ... it'll be like this forever ... I'm spoiling everything"). The third element, helplessness and hopelessness ("There's no way out ... I can't sort this ... It's all just too much").

And of course, when those emotions take hold and start to impact on partner, family and friends, the negativity magnifies. The patient feels even more to blame, because she is now badly affecting those around her. She feels more and more helpless because couple arguments, family squabbles, withdrawal of friendship and run-ins with children are overwhelming her.

\section{Can we help?}

So, what can be done? Simply understanding this model can in itself help the patient feel more in control, more focused and more able to deal with the situation. But more is needed. One option would be the counselling route: a trained therapist could work with the patient to delve into any emotional vulnerability created in early childhood; encourage cognitive analysis of the negative thought patterns; challenge self-blame, low self-belief, generalising, catastrophising and helplessness. Over the course of several sessions, it is possible to reverse the direction of the pessimism and build mental habits of selfcredit, self-confidence, hopefulness and positivity; hence referring a patient on to such a counsellor would be an excellent way forward.

\section{There are still few cohesive models of the psychological structure of PMS.}

But let's get real here. On the National Health Service, where counselling is available, it is strictly rationed; where it is not available, only a minority of patients can afford private care. So the ball is back in the court of health professionals on the front line, with typically just 10 minutes' consultation time. We don't have the opportunity to do any more than diagnose and prescribe.

Or do we? Reading Seligman's work, what I realise is that given the very specific nature of PMS, perhaps we do have an opportunity to do more. Because, for many reasons, it is possible for PMS patients to think about their condition in a particular way that offsets much of their pessimism. If we can use our brief consultation to help them to rethink their situation, then we could make a huge difference. Let me explain.

\section{Three ways to zap out PMS pessimism}

First, PMS is a physical condition. It has physical symptoms that are easily charted, and with a wealth of research to diagnose and explain them. And that in itself 


\section{Box 1: Three simple rules for PMS consultations}

- To offset self-blame: name and objectify the condition tell the patient that PMS is not her fault.

- To offset generalising and catastrophising: get the patient diarising not just negative PMS symptoms but positive emotions and sensations.

- To offset helplessness and hopelessness: give the patient responsibility; get her involved in treatment.

means that a PMS patient can be helped to realise that what is happening to her - even her down moods and negativity - is absolutely not her fault; it is an illness. That realisation in itself will go a long way to offsetting the self-blame and lack of self-belief that is the first element of PMS pessimism (Box 1).

Next, PMS, unlike most physical conditions, has regular remission; women have 'clear' times when their perspective returns and their thought patterns flip back to the more optimistic side. When that happens, they can often see that the doom and gloom of their PMS weeks are temporary, albeit regular, and that PMS doesn't affect their whole life. If they can hold that thought in mind when they are 'clear' then they can enjoy those periods. That insight will go a long way to neutralising the generalisation and catastrophising.

Finally, although medication is wonderful, patient selfhelp is also vital; taking personal responsibility for nutrition, exercise and other symptom reduction is key when it comes to the physical side of PMS. And that need to take responsibility is, of itself, therapeutic; with encouragement and support, patients can self-help their own physical symptoms. And that increased empowerment will, of course, go a long way towards reducing the helplessness and hopelessness that is the third element of PMS pessimism.

\section{Health professionals can help}

You can probably see where I'm going with this. In all those three areas, health professionals are already resourced to help. All we need to do is to be aware of that, and focus on it in our diagnosis and treatment.

\section{Patient self-help is also vital; taking}

personal responsibility for nutrition,

exercise and other symptom reduction is

key when it comes to the physical side of PMS.

We can, from the outset of the consultation, be clear with the patient that PMS is an illness and absolutely not her fault. We can back that up by referring the patient on to further information that allows her to understand the physiology, and so reinforce the fact that her emotional moods are caused by the condition and are not something that she should blame herself for.

We can move on to suggest - as most PMS treatment programmes do - that the patient diarises her symptoms. This not only, once again, separates out patient and condition; it also allows the patient to realise that PMS is not always and everywhere, and so challenges any

\section{Box 2: Useful resources}

The following resources may be useful to your patients:

- You Can Beat PMS! by Colette Harris and Theresa Cheung (Harper Collins)

- Overcoming PMS the Natural Way by Marilyn Glenville (Piatkus)

- Taking Back the Month by Diana Taylor and Stacey Colino (Perigee Books/Penguin)

- National Association for Premenstrual Syndrome (NAPS). Tel: 0870777 2178. Website: www.pms.org.uk

tendency to generalise and catastrophise. We can further encourage this realisation in follow-up consultations by asking the patient to list not just the negative elements she has experienced 'since last time' but also any positive symptoms and emotions, and so help focus her mind on the good as well as the bad.

Doing all we can to get the patient involved in treatment - rather than simply medicating and prescribing - will help enormously.

Finally, although if counselling is available and needed, it is a fine idea to offer it, we should also encourage selfhelp of any kind. We can suggest a patient reads around the subject and provide her with book lists or useful websites (Box 2). We can offer food plans or exercise regimes. We can direct her to an organisation such as the National Association for Premenstrual Syndrome (NAPS) that helps women cope with PMS. We can give positive feedback when she makes progress in all these areas. Particularly with PMS, doing all we can to get the patient involved in treatment - rather than simply medicating and prescribing - will help enormously.

\section{A way forward}

All the interventions I am suggesting can be done quickly and easily from the springboard of a medical consultation and without any specialist counselling knowledge. The physiological component of PMS means that not all emotional symptoms will disappear with this approach. But it will do a great deal to offset the mental pessimism that, I am increasingly convinced, underpins a huge part of PMS distress.

\section{Acknowledgement}

Martin Seligman's work on positive psychology has been invaluable in developing the ideas presented in this article. Visit www.authentichappiness.sas.upenn.edu for more information on positive psychology.

Statements on funding and competing interests

Funding None identified.

Competing interests None identified.

\section{Author's notes}

This article is based on a presentation given to the National Association for Premenstrual Syndrome's Women's Health Conference on 29 September 2006.

The author is interested in preparing a short leaflet for health professionals explaining this approach and encouraging them to use it in PMS consultations. Any organisation interested in collaborating in this project should contact the author directly.

\section{Visit the Faculty Website at www.fsrh.org}

